\title{
LEVOCETRIZINE DIHYDROCHLORIDE LOADED CHITOSAN NANOPARTICLES: FORMULATION AND IN VITRO EVALUATION
}

\section{Short title: Levocetirizine Dihydrochloride Loaded Chitosan Nanoparticles}

\section{INTRODUCTION}

Levocetirizine dihydrochloride (LCD) is an orally active, third generation non-sedative antihistaminic agent widely used in the treatment of chronic idiopathic urticaria, seasonal allergic rhinitis and hay fever. ${ }^{1,2}$ It has more affinity for $\mathrm{H}_{1}$ receptors when compared to cetirizine hydrochloride (CD). ${ }^{1}$ LCD is rapidly and extensively absorbed after oral administration, with the peak plasma concentration attained in $0.9-1 \mathrm{~h} .{ }^{3} \mathrm{LCD}$ undergoes low degree of first pass metabolism in liver; metabolized to limited extent by oxidative dealkylation to a metabolite negligible antihistaminic activity. It is approximately $93 \%$ bound to plasma proteins and plasma elimination half-life of 8-9 h that does not change with multiple dosing. ${ }^{4}$

The fast disintegration behavior of conventional LCD formulations may result in initial burst-released kinetics, permitting the drug to be absorbed very quickly and resulting in high serum concentrations. Under these conditions, local irritation to gastrointestinal (Gl) mucous membranes and other side-effects such as drowsiness, tiredness, dry mouth, fever, cough, oculogyric crisis and somnolence are inevitable. ${ }^{2,5}$ Therefore, it is desirable to design and develop a rational delivery system for LCD.

Many efforts towards designing $C D$ and $L C D$, active enantiomer of $C D$, sustained delivery systems by encapsulating, forming flexible vesicles, microparticles and nanoparticles were made during the last decade.,2,4,56 Nanoparticles attracted considerable attention due to their advantageous properties such as decreased particle size, increased surface area, enhanced reactivity, promoted drug release, reformed targeting, reduced toxicity and improved sustained-release efficacy. ${ }^{7}$

Surface charges of nanoparticles have significant effect on internalization with the cells and also on their uptake. Positively charged nanoparticles seem to allow higher extent of internalization apparently as a consequence of ionic interactions established between cationic nanoparticles and negatively charged membranes. ${ }^{8}$

Chitosan is a polycationic polymer that is naturally occurring polysaccharide found abundantly in marine crustaceans, insects and fungi. ${ }^{9,10}$ Chitosan is composed of 2amino-2-deoxy- $\beta$-D-glucan combined with glycosidic linkages. ${ }^{11}$ Positively charged 
amino groups of polymer interact the negatively charged biological membranes ensuring a mucoadhesive character to the chitosan matrices. ${ }^{12}$ Chitosan is one of the most extensively studied material in the pharmaceutical field. Properties such as biodegradability, low toxicity, good biocompatibility and no risk of accumulation/retention in the body make it suitable for use in biomedical and pharmaceutical formulations. ${ }^{13}$

Spray drying represents a single-step, cheap, continuous and scalable process which enables the production of particles with controlled size and morphological aspects. ${ }^{14}$ Spray drying also eliminates the addition of crosslinking agent minimizes the swelling of chitosan based nanoparticles. ${ }^{15}$ Therefore, spray drying technology was utilized in this study for the formulation of cationic nanoparticles using advantages of the method. This study may provide valuable information for the design and development of new LCD loaded controlled-release dosage forms. The aim of the study was to formulate positively charged LCD loaded nanoparticles at submicron level with high encapsulation efficiency, reduction local irritation to gastrointestinal (GI) mucous membranes and other side-effects and prolonged plasma level drug concentration that enhances bioavailability and protection the sensitive drug against light so improvement its stability.

\section{MATERIALS AND METHODS}

\section{Materials}

LCD was a kind gift from Neutec (İstanbul, Turkey). Chitosan (low molecular weight with 20-200 mPas.sec viscosity) were purchased from Sigma (Steinheim, Germany). All other reagents used were of analytical grade.

\section{Preparation of Nanoparticles}

Chitosan nanoparticles were prepared using Mini Spray Dryer (B-190, BUCHI, Switzerland). The spray dryer was connected to the Inert Loop B-295 (Buchi Labortechnik AG, Switzerland) due to the organic solvent. Carbon dioxide gas was used at a flow rate of $120 \mathrm{~L}^{\mathrm{min}} \mathrm{m}^{-1}$. The residual oxygen level in the system was controlled below $4 \%$.

When preparing particulate systems by spray-drying method, it has to be kept in the mind that production parameters such as size of nozzle, feeding pump rate, inlet temperature and compressed air flow rate, affect the particle size. ${ }^{15,16}$ It was reported that smaller particles are formed with lower feeding pump rate and smaller nozzle size. 
In addition smaller particles are formed with greater volume of air input where particle size is not dependent inlet temperature in the range of $120-180^{\circ} \mathrm{C} . .^{15}$ Therefore the inlet temperature was maintained at $120^{\circ} \mathrm{C}$ using the slowest pump rate as can be spray the solution.

Accurately weighed chitosan (1g) was dissolved in acetic acid solution (2\% v/v, 120 $\mathrm{mL})$. Ethanol (96\% v/v, $120 \mathrm{~mL}$ ) was added to the acidic solution in order to decrease the viscosity of chitosan solution. LCD was added to the mixture under constant stirrer speed (300 rpm) on a magnetic stirrer. The final clear solution was then spray-dried with an inlet temperature of $120^{\circ} \mathrm{C} \pm 1^{\circ} \mathrm{C}$ and outlet temperature of $60^{\circ} \mathrm{C} \pm 5^{\circ} \mathrm{C}$ and delivered to a drying zone with a $4 \mu \mathrm{m}$ nozzle. White dry powders were obtained and kept in tightly closed vials at room temperature until being analyzed. Placebo nanoparticles were prepared as described above without the addition of active agent. Spray-drying conditions were shown in Table 1.

Table 1. Spray-drying conditions

\begin{tabular}{ccccc}
\hline $\begin{array}{c}\text { Inlet } \\
\text { temperature }\end{array}$ & $\begin{array}{c}\text { Outlet } \\
\text { temperature }\end{array}$ & $\begin{array}{c}\text { Flow rate } \\
\mathrm{mL} / \mathrm{min}\end{array}$ & $\begin{array}{c}\text { Pump control } \\
\text { level }\end{array}$ & $\begin{array}{c}\text { Aspirator } \\
\text { control level }\end{array}$ \\
\hline $120^{\circ} \mathrm{C}$ & $60^{\circ} \mathrm{C}$ & 450 & 3 & 3 \\
\hline
\end{tabular}

\section{Characterization of Nanoparticles}

\section{Morphology}

The particle shape and surface characteristics of the freshly prepared nanoparticle formulations and LCD were investigated by scanning electron microscope (SEM) (HITACHI TM3030Plus Tabletop Microscope, Japan) at $25^{\circ} \mathrm{C} \pm 2^{\circ} \mathrm{C}$. Samples were coated with a thin layer gold under argon to avoid charging under the electron beam.

\section{Particle size and zeta potential}

Particle size, polydispersity index $(\mathrm{PI})$ and zeta potential measurements were carried out on freshly prepared samples using Malvern Nano ZS (Zetasizer Nano Series, Worcestershire, UK). Samples of all nanoparticles were dispersed in double distilled water (adjusted to a constant conductivity of $50 \mu \mathrm{S} . \mathrm{cm}^{-1}$ using $0.9 \% \mathrm{NaCl}$ ) just prior to analyses. All analyses were repeated in triplicate at $25^{\circ} \mathrm{C} \pm 2^{\circ} \mathrm{C}$.

The data obtained were evaluated by span values that calculated using volume distribution as diameter (d) values of $10 \%, 50 \%$ and $90 \%$. The diameter values indicate the percentage of particles possessing a diameter equal to or lower than the given 
value. The Span value is a statistical parameter useful to evaluate the particle size distribution and calculated applying the following equation ${ }^{17}$ :

Span value $=[d(90)-d(10)] / d(50)$

\section{Differential scanning calorimetry (DSC)}

Structural and crystallinity changes of LCD and the polymer due to the thermal impacts during the formulation steps were evaluated using differential scanning calorimetry (DSC; DSC-60, Shimadzu Scientic Instruments, Columbia, MI, USA). Analyses were performed under nitrogen at a flow rate of $50 \mathrm{~mL} \cdot \mathrm{min}^{-1}$ at $30-250^{\circ} \mathrm{C}$ with an increase rate of $10^{\circ} \mathrm{C} \cdot \mathrm{min}^{-1}$.

\section{Fourier transform infrared spectrophotometry (FT-IR)}

Fourier transform infrared spectrophotometric (FT-IR) analysis spectra were recorded using Shimadzu IR Prestige-21 (Shimadzu Corporation, Kyoto, Japan) at the wavelength range of $4000-500 \mathrm{~cm}^{-1}$.

\section{Nuclear magnetic resonance spectroscopy ( $\left.{ }^{1} \mathrm{H}-\mathrm{NMR}\right)$}

Nuclear magnetic resonance spectroscopy ( $\left.{ }^{1} \mathrm{H}-\mathrm{NMR}\right)$ analyses were performed using UltraShield $^{\text {TM }}$ CPMAS NMR (Brucker, Rheinstetten, Germany). Samples were prepared by dissolving nanoparticles in deuterated dimethyl sulfoxide.

Pure chitosan and LCD were analyzed by DSC, FTIR and ${ }^{1} \mathrm{H}-\mathrm{NMR}$ were used as reference evaluating the interaction between polymer and LCD.

\section{Determination of levocetirizine dydrochloride}

A high performance liquid chromatographic (HPLC) method was used for the determination of LCD. Shimadzu 20-A (Tokyo, Japan) equipped with reversed phase Nucleosil 120-5 column (column diameter: $4.6 \mathrm{~mm}$, column length: $250 \mathrm{~mm}, \mathrm{C}_{18}$ Gravity, $5 \mu \mathrm{m})$ was used as instrument. Acetonitrile: Water: $1 \mathrm{M}$ sulfuric acid (93:66:4, $\mathrm{v} / \mathrm{v} / \mathrm{v}$ ) was used as a mobile phase with a flow rate of $1 \mathrm{~mL} \cdot \mathrm{min}^{-1} ; 20 \mu \mathrm{L}$ constant amount of samples was injected via an Automatic Injector (Shimadzu, Tokyo, Japan) was used and Photodiode detector was used at $230 \mathrm{~nm} .{ }^{18}$ Column temperature was set to $30^{\circ} \mathrm{C}$. Validation studies were carried out for data reliability.

\section{Encapsulation efficiency (EE\%)}

In order to determine the amount of LCD in drug loaded nanoparticles, drug encapsulation efficiency study was performed by validated HPLC method. Accurately weighed nanoparticles $(5 \mathrm{mg})$ were dispersed in acetonitrile $(1 \mathrm{~mL})$, vortexed for $1 \mathrm{~min}$ and centrifuged at $2500 \mathrm{rpm}$ for $5 \mathrm{~min}$ for the determination of LCD remaining on chitosan sphere surface $(L C D s) .{ }^{12}$ The quantity LCD encapsulated in nanoparticles 
was calculated as the difference between the initially added (LCDt) and the LCDs. ${ }^{5}$ Each experiment was repeated three times.

$E E \%=\left[\left(L C D_{t}-L C D_{s}\right) / L C D_{t}\right] \times 100$

\section{In vitro drug release}

A dialysis membrane method was used to identify release behavior of nanoparticles. In vitro release profiles of LCD were investigated in freshly prepared simulated intestinal fluid (SIF, pH 6.8) for a period of 72 hours. Briefly, drug loaded nanoparticles containing $1.5 \mathrm{mg}$ LCD were put in dialysis bag (with a molecular cut off $12-14 \mathrm{kD}$, Sigma) and capped with closures. Bags were immersed into dissolution medium containing $80 \mathrm{~mL} \mathrm{SIF} \mathrm{at} 37^{\circ} \mathrm{C} \pm 1^{\circ} \mathrm{C}$ on a water bath using continuous magnetic stirring rate of $100 \mathrm{rpm}^{7} 1 \mathrm{~mL}$ of samples were withdrawn at predetermined time intervals and LCD contents in the receptor chamber were determined by HPLC method and release profile of pure LCD wad used as reference for better evaluation of the profiles. Sink conditions were maintained in the receptor compartment during in vitro release studies. Each experiment was repeated three times.

\section{In vitro release kinetics}

Release kinetics were investigated using DDSolver software in order to evaluate the mechanism of drug release from nanoparticles. ${ }^{19}$

\section{RESULTS AND DISCUSSION}

Different methods were used to prepare chitosan nanoparticles. Preference of the method depends on factors such as particle size, thermal and chemical stability of the active agent, reproducibility of the release profiles, stability of the final product and residual toxicity associated with the final product. ${ }^{11}$

Spray-drying is a well-known technique to produce powders, granules or agglomerates from the mixture of drug and excipient solutions as well as suspensions. ${ }^{15}$ In this study, spray-drying method was chosen for preparing chitosan nanoparticles since it does not involve toilsome procedures and avoids the use of harsh cross-linking agents and organic solvents which might possibly trigger chemical reactions with the active agent. $^{11}$

Compositions of the chitosan nanoparticles prepared were given in Table 2. 
Table 2. Compositions of nanoparticles prepared.

\begin{tabular}{ccccc}
\hline Code & Chitosan (g) & LCD (g) & $\begin{array}{c}\text { Acetic acid solution }(\mathbf{2} \%, \mathbf{v} / \mathbf{v}, \\
\mathbf{m L})\end{array}$ & Methanol $(\mathbf{m L})$ \\
\hline Placebo & 1 & - & 120 & 120 \\
F-1 & 1 & 0.05 & 120 & 120 \\
F-2 & 1 & 0.1 & 120 & 120 \\
\hline
\end{tabular}

\section{Characterization of Nanoparticles}

\section{Morphology}

SEM images of pure LCD and polymeric nanoparticles were given in Figure 1. SEM images showed that all formulations prepared were in spherical shape. 5 Placebo nanoparticles' images reminded the collapsed balloons with wrinkled surfaces (Figure 1b), while LCD loaded spray-dried formulations demonstrated spherical shapes that are the general morphology of spray-dried amorphous materials. ${ }^{12,20}$ Crystalline structure of LCD was not observed in the formulations indicating successful incorporation of LCD into polymeric matrices.

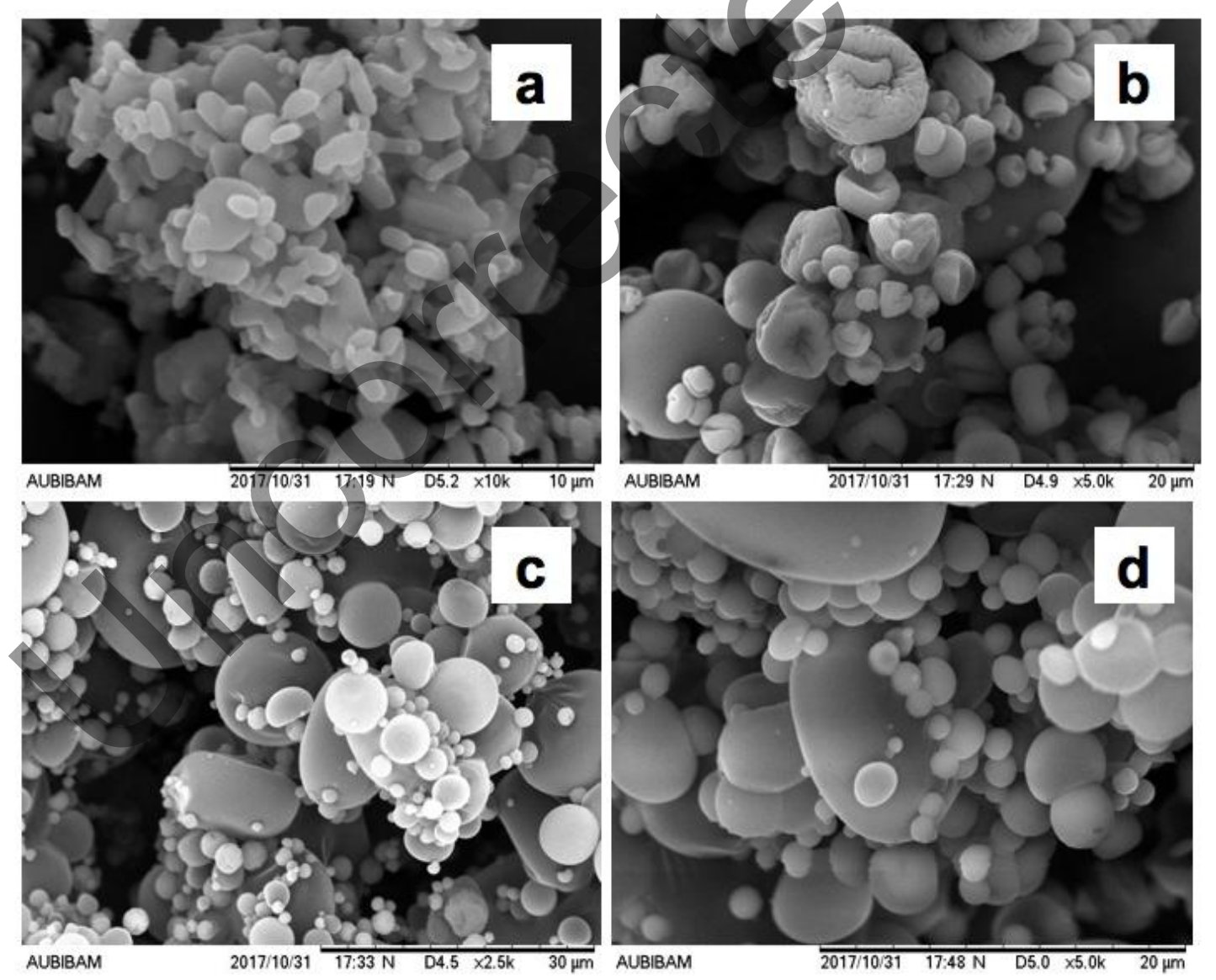

Figure 1. SEM Images of pure LCD and formulations a: LCD, b: Placebo c: F-1 d: F-2 


\section{Particle size and zeta potential}

Mean particle size, $\mathrm{PI}$ and zeta potential values of chitosan nanoparticles were presented in Table 3. Particle size and size distribution of nanoparticles play a key role in their adhesion and interaction with cells. ${ }^{7}$ Particle sizes of nanoparticles were found to be $521.70 \pm 8.50 \mathrm{~nm}$ and $538.46 \pm 5.74 \mathrm{~nm}$ for F-1 and F-2, respectively. It was found that decrease in the amount of LCD in nanoparticles was in parallel with the relative decrease in average particle size. ${ }^{21}$

Table 3. Mean particle size, PI, zeta potential of formulations prepared (SD: Standard Deviation, SE: Standard Error) $(n=3)$

\begin{tabular}{ccccc}
\hline Code & $\begin{array}{c}\text { Particle size }(\mathrm{nm}) \\
\mathbf{S} \text { SE }\end{array}$ & PI \pm SE & $\begin{array}{c}\text { Span values } \pm \\
\text { SD }\end{array}$ & $\begin{array}{c}\text { Zeta Potential }(\mathrm{mV}) \\
\pm \text { SE }\end{array}$ \\
\cline { 2 - 5 } Placebo & $487.42 \pm 7.25$ & $0.426 \pm 0.085$ & $0.782 \pm 0.058$ & $24.3 \pm 2.1$ \\
\hline F-1 & $521.70 \pm 8.50$ & $0.512 \pm 0.090$ & $0.992 \pm 0.073$ & $25.7 \pm 1.8$ \\
\hline F-2 & $538.46 \pm 5.74$ & $0.498 \pm 0.074$ & $0.855 \pm 0.081$ & $25.9 \pm 2.5$ \\
\hline
\end{tabular}

PI values used to define the particle size distribution. All prepared nanoparticles were nanometer sized and the size distributions were relatively monodisperse with the $\mathrm{PI}$ values $0.512 \pm 0.090$ and $0.498 \pm 0.074$ for $F-1$ and $F-2$, respectively. When $P I$ values were higher than 0.7 are indicative of a very large particle size distribution. ${ }^{22,23}$ All nanoparticles prepared in this study presented PI values lower than 0.7 , therefore particle size distribution was decided to be uniform.

The span index measures the width of the particle size distribution, as described in the literature. ${ }^{24}$ Formulations show a relatively narrow particle size distribution (span index $<1)$. The narrower size distribution reported previously was confirmed by the span values, i.e. the lower span the narrower is the particle size distribution. ${ }^{17}$

Zeta potential is a scientific notion for electrokinetic potential in colloidal systems which is one of the most important properties playing a major role in efficiency of nanomedicine. Zeta potential can affect the physical and the pharmacokinetic properties of nanosystems in the body or may affect the phagocytosis of the nanoparticles in the blood stream. ${ }^{25}$

Results showed that zeta potentials measured were $25.7 \pm 1.8 \mathrm{mV}$ and $25.9 \pm 2.5 \mathrm{mV}$ for F-1 and F-2, respectively, which may be attributed to the positive charges on polymeric matrices indicating adequate physical stability. Considering negatively 
charged cell membranes, cationic nanoparticles have great potential in the enhancement of the internalization with the cells and also on their uptake. ${ }^{15,26}$

\section{Differential scanning calorimetry (DSC)}

Thermodynamic variations related to morphological changes during and after formulation steps can be detected by thermal analysis. ${ }^{27}$ Figure 2 displays the thermal behavior of the LCD and nanoparticles prepared. Pure LCD demonstrated endothermic peak at $228^{\circ} \mathrm{C}$ showing to crystalline structure. ${ }^{28}$ According to DSC analyses, no endothermic peaks were revealed in the thermograms of the nanoparticles prepared showing the amorphous state of the polymeric lattice. The disappearance of LCD peak in all thermograms of nanoparticles prepared indicated LCD was molecularly dispersed in the polymeric structure. ${ }^{7,21,23}$

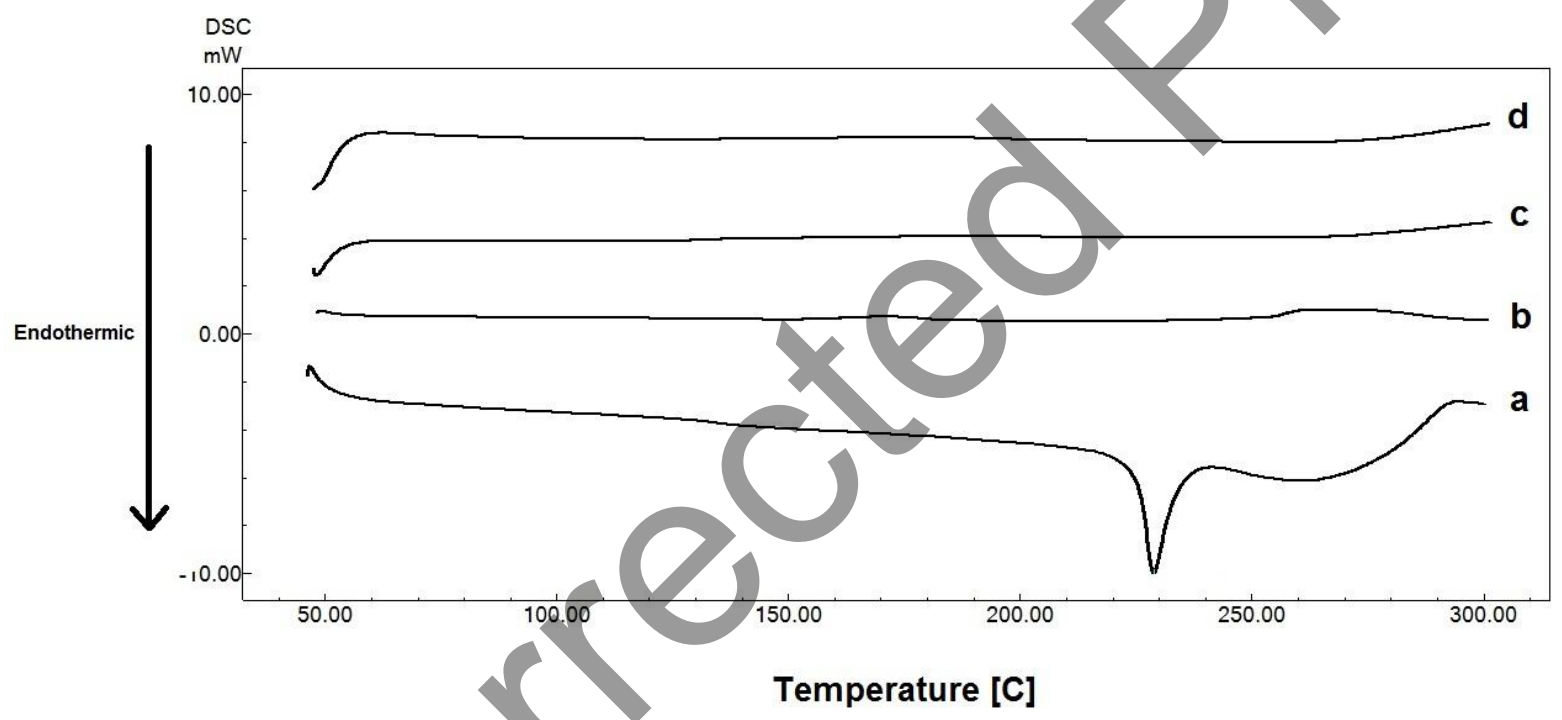

Figure 2. DSC thermograms of pure LCD and formulations a: LCD, b: Placebo c:

\section{F-1 d: F-2}

\section{Fourier transform infrared spectrophotometry (FT-IR)}

FTIR spectroscopy reveals information about the molecular interactions of chemical components and is beneficial to assess microstructural changes in the polymeric structure.

The FTIR spectrum of LCD showed bands assigned to the aromatic $-\mathrm{CH}$ (3110-3000 $\left.\mathrm{cm}^{-1}\right)$ and aliphatic $-\mathrm{CH}_{2}\left(2985.6-2914.2 \mathrm{~cm}^{-1}\right)$. While the $\mathrm{OH}$ dimer of the aminocarboxylic acid appeared at $2628.98 \mathrm{~cm}^{-1}$, the tertiary amine salt observed at 2349.30 $\mathrm{cm}^{-1}$. Absorption bands at $1745.58 \mathrm{~cm}^{-1}$ and $1600.32 \mathrm{~cm}^{-1}$ were a result of carbonyl group and phenyl nucleus skeletal stretching, respectively. The presence of two adjacent benzene rings were shown at $844.8-808.1 \mathrm{~cm}^{-1}$. While the carboxylic C-O 
bond frequency observed at $1463-1263 \mathrm{~cm}^{-1}$, the aliphatic chain $\mathrm{C}-\mathrm{O}$ bond in $\mathrm{CH}_{2} \mathrm{CH}_{2} \mathrm{OCH}_{2} \mathrm{COOH}$ appeared at $1180.4 \mathrm{~cm}^{-1}$ and at $758 \mathrm{~cm}^{-1} .30$

Placebo formulation showed similar absorption bands with pure chitosan. FTIR spectrum of placebo formulation showed characteristic absorption bands at 3352, 2918 and $2850 \mathrm{~cm}^{-1}$ which represent $-\mathrm{OH},-\mathrm{CH}_{2}$ and $\mathrm{CH}_{3}$ aliphatic groups, and bands at 1558 and $1417 \mathrm{~cm}^{-1}$ that represent $-\mathrm{NH}$ group bending vibration and vibrations of $-\mathrm{OH}$ group of the primary alcohol, respectively. Amino group has a characteristic band $3400-3500 \mathrm{~cm}^{-1}$ which is concealed by the broad absorption band of $-\mathrm{OH}$ groutp. ${ }^{31}$

Distinctive peaks of LCD were not seen in the spectra of both F-1 and F-2 formulations indicating the molecular dispersion of LCD in the polymeric matrice which was supported by the DSC results. ${ }^{7}$ The absence of LCD distinctive peaks confirmed encapsulation of drug within the polymeric structure. ${ }^{6}$

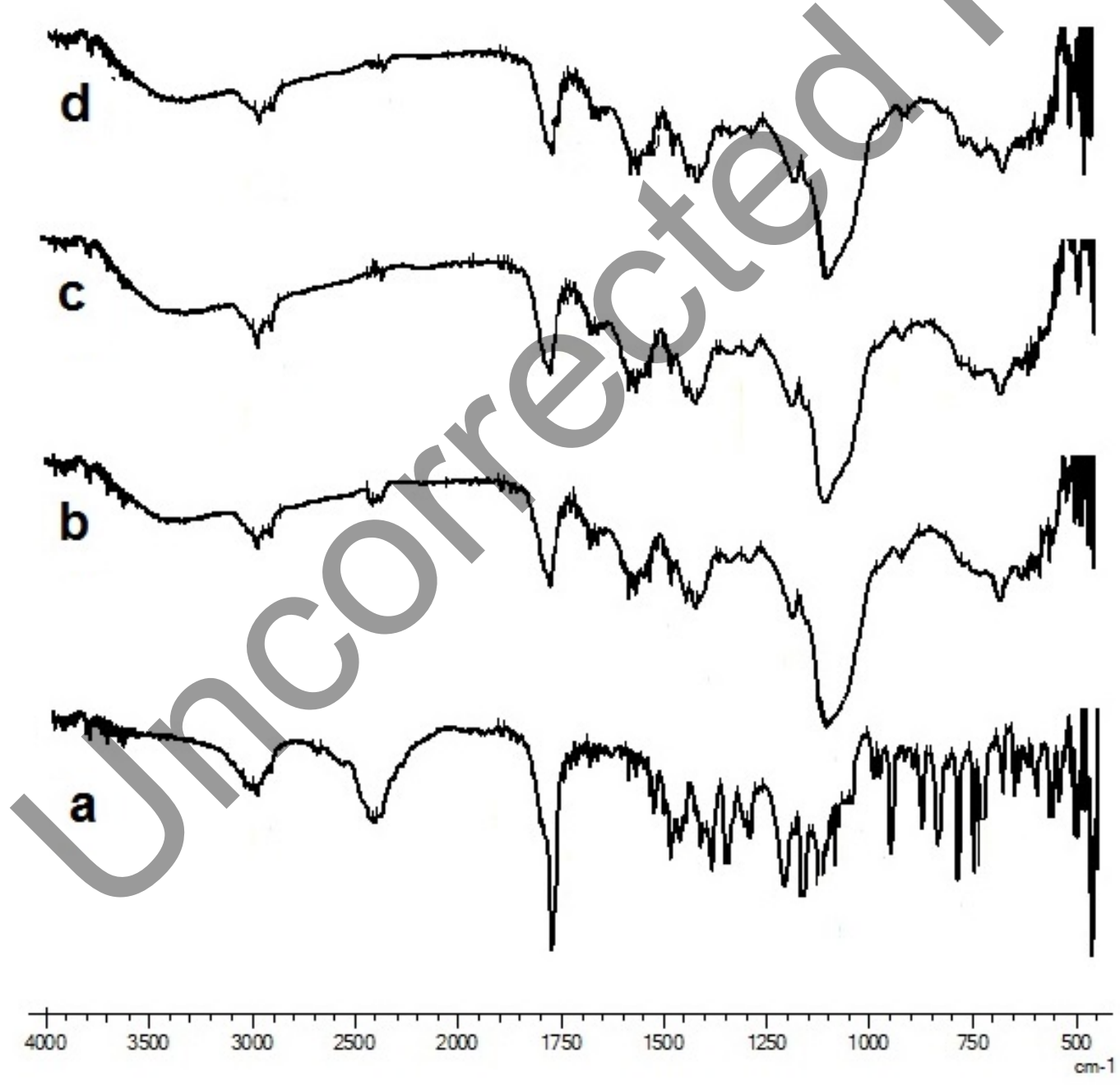

Figure 3. FTIR spectra of pure LCD and formulations a: LCD, b: Placebo c: F-1 d: F-2 


\section{Nuclear magnetic resonance spectroscopy (NMR)}

Physicochemical properties of nanoparticles can be identified by NMR analysis in a variety of dosage forms to elucidate the status of active agent incorporated into matrice, its molecular mobility and molecular interactions between the active agent and the excipients. ${ }^{12}$ Peaks appeared in the broad multiplet between 7-8 ppm belong to peaks of 16 aromatic $\mathrm{CH}$ protons and $2 \mathrm{NH}$ protons. ${ }^{32} \mathrm{~A}$ singlet was observed at 3.33 ppm for methyl diphenyl $\mathrm{CH}$ proton. Triplet at $3.83 \mathrm{ppm}$ was obvious due to four protons on the acyclic $\mathrm{CH}_{2}$ groups. Another singlet at $3.51 \mathrm{ppm}$ with two protons was shown for the $\mathrm{CH}_{2}$ in $\mathrm{CH}_{2} \mathrm{CH}_{2} \mathrm{O}$ entity. The $\mathrm{CH}_{2}$ in the $\mathrm{CH}_{2} \mathrm{COOH}$ group appeared as a singlet $3.73 \mathrm{ppm}$. A very weak singlet was present at $10.6 \mathrm{ppm}$ for the one proton of the carboxylic acid group. ${ }^{33}$ Some of characteristic peaks of LCD were found also in the spectra of nanoparticle formulations indicating successful incorporation of drug into the nanoparticles with no chemical changes.$^{34}$ Data were also supported by DSC and FTIR results. 


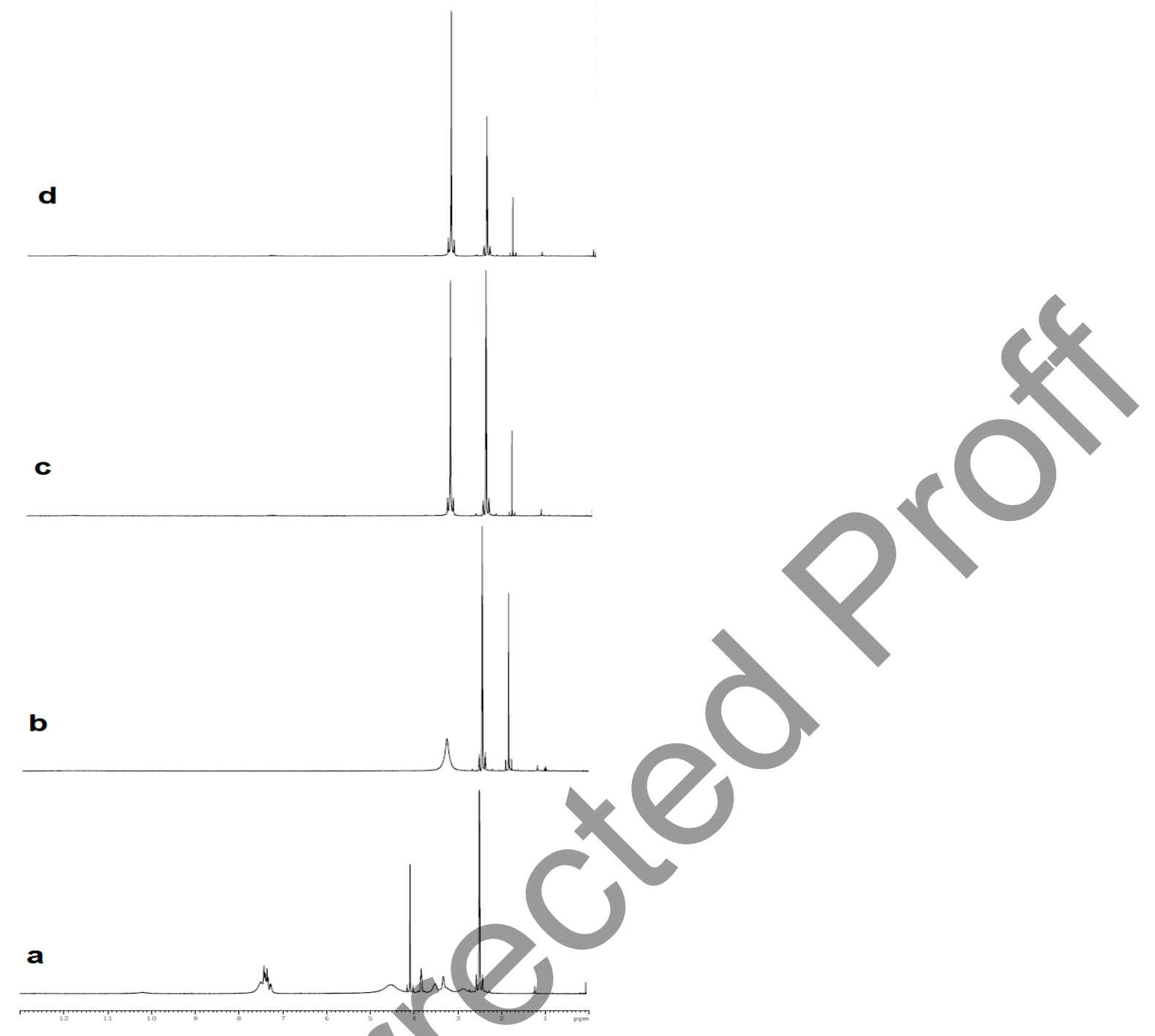

Figure 4. NMR spectra of pure LCD and formulations a: LCD, b: Placebo c: F-1 d: F-2

\section{Determination of levocetirizine dihydrochloride}

Analytical process validation method of International Harmonization Committee was used in this study. The method was validated for linearity, accuracy, precision, sensitivity and specificity with reference to the guidelines. ${ }^{35}$ The separation and resolution of the LCD from formulations could be achieved using a mixture of acetonitrile: water: $1 \mathrm{M}$ sulfuric acid $(93: 66: 4, \mathrm{v} / \mathrm{v} / \mathrm{v})$ as the mobile phase with UV detection at $230 \mathrm{~nm} .{ }^{18}$

The calibration curve was constructed by plotting the peak area ratio $(y)$ of the LCD concentration. The linearity of the method was examined in the range of 2.5-250 $\mu \mathrm{g} \cdot \mathrm{mL}^{-1}$ and the calibration curve were chosen in this range (Figure 5). Good correlation fit the equation as $y=2398.3252 x+6416.2523$ with correlation coefficient 
of 0.9996 . The limit of detection (LOD) and limit of quantification (LOQ) values were determined to be $0.7968 \mu \mathrm{g} \cdot \mathrm{mL}^{-1}$ and $2.4146 \mu \mathrm{g} \cdot \mathrm{mL}^{-1}$, respectively.

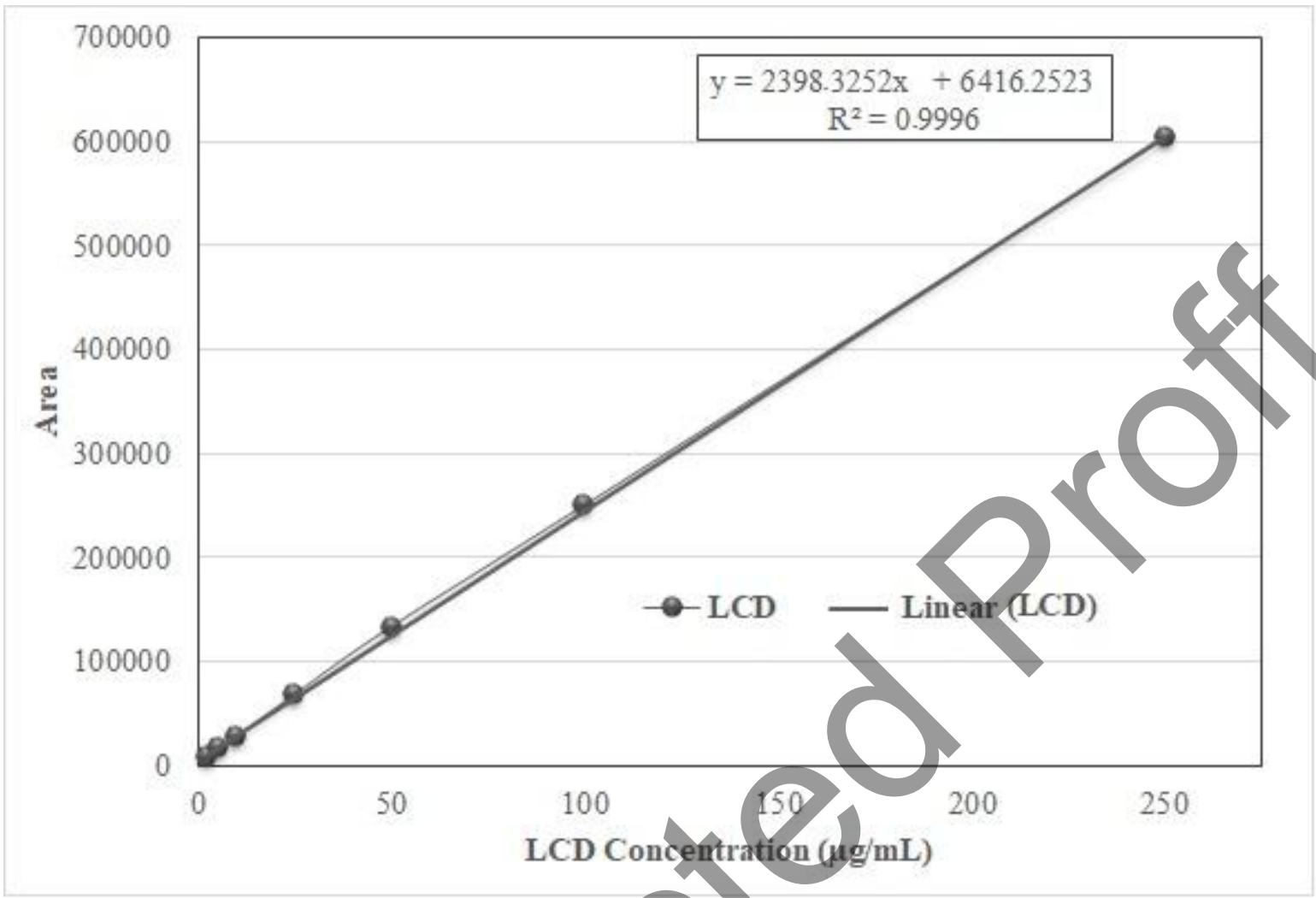

\section{Figure 5. Calibration curve of LCD}

Accuracy is the similarity of the test results obtained by the analytical method to the true values. It was reported that recovery values must be in the range of $98-102 \%$ to decide on the accuracy of the method used. HPLC method used in this study yielded high recovery values (98-100\%) (Table 4) which indicated the accuracy of the method used. Measurements performed on three different concentrations (low, medium and high) evaluating repeatability and reproducibility of the analytical method used seem to verify the precision of the method since the percentage of relative standard deviation (RSD) was found to be below $2 \%$ which is within the targeted interval (Table 5). ${ }^{36}$ Meanwhile this method was specific for the determination and quantification of LCD.

Table 4. Accuracy and recovery results

\begin{tabular}{lllll}
\hline LCD $\left(\boldsymbol{\mu g} \cdot \mathbf{m L}^{-1}\right)$ & Recovery $\left(\boldsymbol{\mu g} \cdot \mathbf{m L}^{-1}\right)$ & Recovery $(\%)$ & SE & RSD \\
\hline 5 & 4.9039 & 98.0775 & 0.7582 & 1.3391 \\
50 & 50.0427 & 100.0855 & 1.4125 & 2.4445 \\
250 & 248.8017 & 99.5207 & 0.1239 & 0.2157 \\
\hline
\end{tabular}

SE: Standard error; RSD: Relative standard Deviation 
Table 5.Interday and intra-day precision results

\begin{tabular}{|c|c|c|c|c|c|}
\hline \multirow[t]{2}{*}{ LCD $\left(\mu \mathrm{g} \cdot \mathrm{mL}^{-1}\right)$} & \multicolumn{4}{|c|}{ Intra-day $(n=3)$} & \multirow{2}{*}{$\begin{array}{l}\text { Inter-day } \\
(n=9)\end{array}$} \\
\hline & & Day 1 & Day 2 & Day 3 & \\
\hline \multirow[t]{3}{*}{5} & Mean area & 18466 & 18137 & 18203 & 18269 \\
\hline & & 0.0981 & 0.0885 & 0.0666 & 0.0725 \\
\hline & RSD & 1.9535 & 1.8111 & 1.3560 & 1.4680 \\
\hline \multirow[t]{3}{*}{50} & Mean area & 132707 & 132835 & 12858 & 131353 \\
\hline & & 0.2954 & 0.8360 & 0.6790 & 1.0241 \\
\hline & RSD & 0.5610 & 1.5860 & 1.3336 & 1.9660 \\
\hline \multirow[t]{3}{*}{250} & Mean area & 609100 & 610793 & 603723 & 607842 \\
\hline & SD & 0.4775 & 0.7398 & 0.7237 & 1.5391 \\
\hline & RSD & 0.1900 & 0.2936 & 0.2906 & 0.6137 \\
\hline
\end{tabular}

Method validation conducted proved accuracy, reliability and specificity of the method. It was found that all the results of present coefficient of variation are below $2 \%$ showing the method was valid. ${ }^{37,38}$

\section{Encapsulation efficiency (EE\%)}

The encapsulation efficiency explains that it is the percentage of the amount of the drug that loaded to polymeric matrices. In this study, EE \% was determined to be 71.37 \pm 1.32 and $67.328 \pm 2.09$ (EE \% \pm SE) for F-1 and F-2, respectively. Drug-polymer compositions is most likely one of the factor for in vitro release rate, however it seems that a complex phenomenon between active agent and polymer molecules may occur, including entrapment of drug within polymeric network and the adsorption of drug molecules on the surface of polymeric matrices as a result of electrostatic adhesions. ${ }^{39,40}$

\section{In vitro drug release}

Dissolution testing has been recognized as an important tool of both drug development and quality control. ${ }^{41}$ It can be used not only as a primary tool to monitor the consistency and stability of drug products but also as a relatively rapid and inexpensive technique to predict in vivo absorption of a drug formulation. ${ }^{19}$

Release profiles obtained from chitosan nanoparticles were given in Figure 6 . The release profile of pure LCD was used as reference. LCD release from nanoparticles was much slower than its pure form showing time dependent release manner in release media. Also there was no significant difference between F-1 and F-2 formulations as stated by the release profiles $(p>0.05) .{ }^{21}$ The release rate was not affected significantly by increasing the amount of LCD used in the nanoparticles. Moreover, drug release was extended more than 2 fold with nanoparticles which enhances the possible use of them for better treatment. 


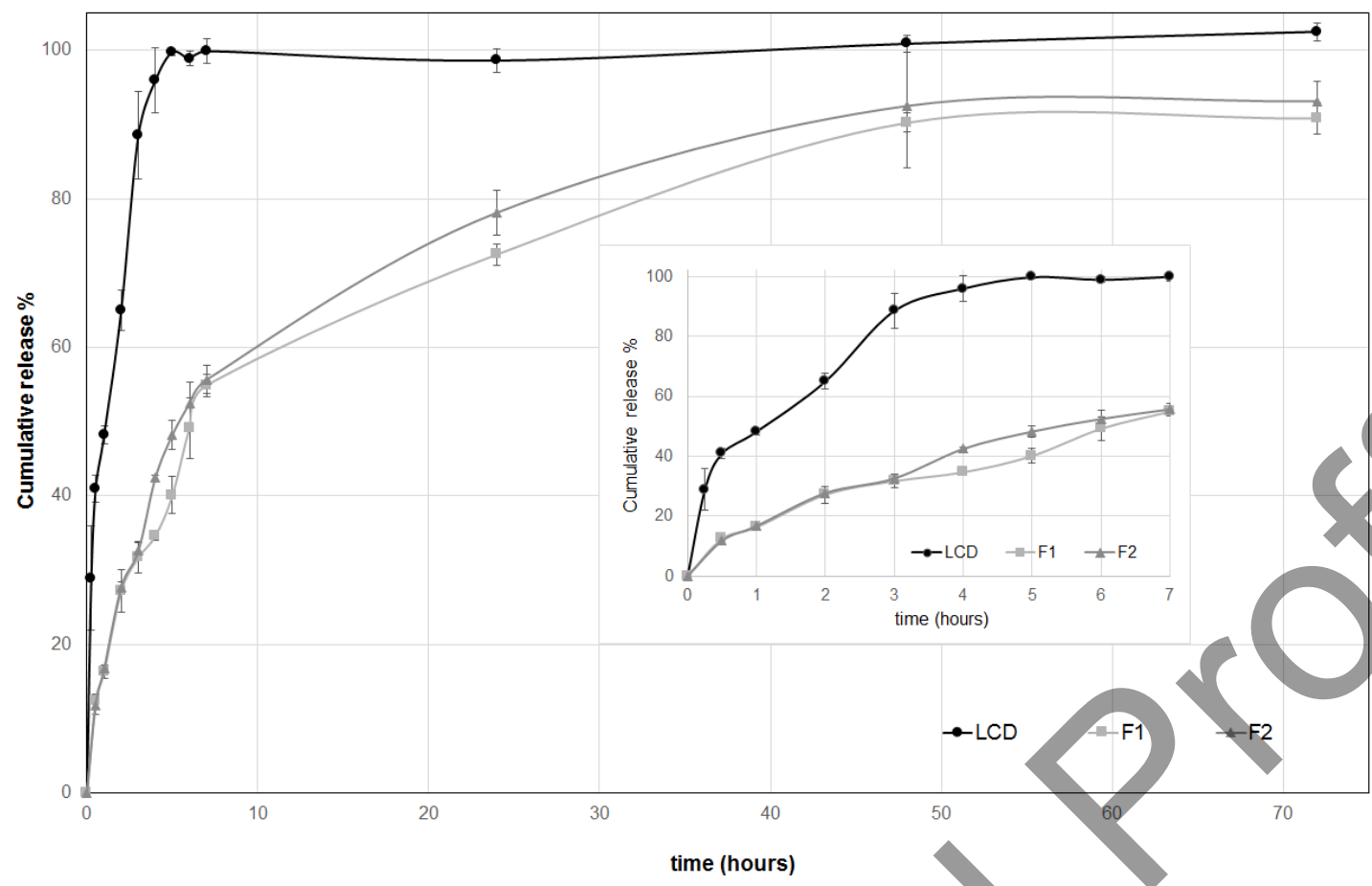

Figure 6. In vitro release profiles of LCD from nanoparticles prepared $(n=3)$ (mean \pm standard error)

\section{In vitro release kinetics}

Quantitative evaluation of drug dissolution characteristics is a great interest to pharmaceutical scientists. Drug release data were evaluated using many mathematical and statistical parameters. ${ }^{19}$

Fitting in vitro release profiles to mathematical models which describes drug release as a function of time gives valuable data about the in vivo release behavior of optimal delivery system. ${ }^{42}$ Therefore, in vitro release kinetics were also evaluated for nanoparticles in comparison with pure LCD using DDSolver Program. ${ }^{19}$

In vitro dissolution data were transferred to the DDSolver program to determine five important and the most popular criteria. These criteria were based on the coefficient of determination (Rsqr, $R^{2}$ or COD), the adjusted coefficient of determination $\left(R^{2}\right.$ adjusted), the Akaike Information Criterion (AIC), the Model Selection Criterion (MSC) and $\mathrm{n}$ for only Korsmeyer-Peppas models. The highest $\mathrm{R}^{2}, \mathrm{R}^{2}$ adjusted and MSC values and the lowest AIC values were used for the evaluation of the best fitted models. . $^{19,43}$ Zero-order kinetics, first-order kinetics, Higuchi, Hixson-Crowell, Korsmeyer-Peppas and Hopfenberg models were selected for evaluation in DDSolver program. The majority of these models usually have nonlinear equations. The DDSolver computer program has been developed to utilise the hardships encountered in comparing free 
profiles with several different dissolution parameters for eliminating many experimental mistakes and the other mistakes that belong to the user. ${ }^{19}$

As a result of applying in vitro release study data obtained to different kinetic models using DDSolver program; $\mathrm{R}^{2}, \mathrm{R}^{2}$ adjusted, MSC, AIC values were shown in Table 6.

Table 6. Release kinetic modeling of LCD loaded nanoparticles

\begin{tabular}{|c|c|c|c|c|c|c|c|}
\hline \multirow{2}{*}{ Code } & \multirow{2}{*}{ Model and Equation } & \multicolumn{6}{|c|}{ Evaluation Criteria } \\
\hline & & $k$ & $R^{2}$ & $R^{2}$ adjusted & AIC & MSC & \\
\hline LCD & \multirow{3}{*}{$\begin{array}{c}\text { Zero-order model } \\
\qquad F=k_{0}^{*} t\end{array}$} & 2.100 & -8.446 & -8.446 & 120.841 & 2.75 & \\
\hline F-1 & & 1.682 & -0.180 & -0.180 & 101.939 & & - \\
\hline F-2 & & 1.745 & -0.335 & -0.335 & 700.0 & -0.471 & - \\
\hline LCD & \multirow{3}{*}{$\begin{array}{l}\text { First-order model } \\
F=100^{\star}\left[1-\operatorname{Exp}\left(-k_{1}^{*} t\right)\right]\end{array}$} & 0.805 & 0.932 & & & 2.504 & - \\
\hline F-1 & & 0.060 & 0.745 & 0.745 & & 1.186 & - \\
\hline F-2 & & 0.068 & 0.741 & 0.741 & 85.904 & 1.169 & - \\
\hline LCD & \multirow{3}{*}{$\begin{array}{c}\text { Higuchi model } \\
\qquad F=k_{\mathrm{H}}^{*} t^{0.5}\end{array}$} & 19.106 & -3.304 & & 112.194 & -1.641 & - \\
\hline $\mathrm{F}-1$ & & 13.298 & & & 82.722 & 1.400 & - \\
\hline F-2 & & 13.931 & & 0.738 & 86.047 & 1.156 & - \\
\hline LCD & \multirow{3}{*}{$\begin{array}{l}\text { Hixson-Crowell model } \\
\qquad F=100^{*}\left[1-\left(1-k_{H C}{ }^{*}\right)^{3}\right]\end{array}$} & 0.027 & -4.977 & -4.977 & 115.807 & -1.970 & - \\
\hline F-1 & & & 0.565 & 0.565 & 90.958 & 0.651 & - \\
\hline $\mathrm{F}-2$ & & & 0.521 & 0.521 & 92.659 & 0.555 & - \\
\hline LCD & \multirow{6}{*}{$\begin{array}{l}\text { Korsmeyer-Peppas* } \\
F=k_{\mathrm{KP}}{ }^{*} t^{n} \\
\text { Hopfen berg model }{ }^{*}\end{array}$} & & -0.321 & -0.468 & 101.200 & -0.642 & 0.000 \\
\hline$F-1$ & & 25.722 & 0,929 & 0,921 & 73.074 & 2.277 & 0.290 \\
\hline F-2 & & 20.211 & 0.843 & 0.826 & 82.370 & 1.490 & 0.420 \\
\hline LCD & & 0.081 & 0.132 & 0.035 & 96.584 & -0.222 & 3.000 \\
\hline$F=1$ & & 0.014 & 0.565 & 0.517 & 92.958 & 0.469 & 3.000 \\
\hline F-2 & & 0.016 & 0.522 & 0.469 & 94.652 & 0.374 & 3.000 \\
\hline
\end{tabular}

*In all models, $\boldsymbol{F}$ is the fraction (\%) of drug released in time $\mathbf{t}, \boldsymbol{k}_{\mathbf{0}}$ : zero-order release constant, $\boldsymbol{k}_{1}$ :first-order release constant, $\boldsymbol{k}_{\mathrm{H}}$ : Higuchi release constant, $\boldsymbol{k}_{\mathrm{HC}}$ :Hixson-crowell release constant $\boldsymbol{k}_{\mathrm{KP}}$ : release constant incorporating structural and geometric characteristics of the drug-dosage form, $\boldsymbol{n}$ : is the diffusional exponent indicating the drug-release mechanism, $\boldsymbol{F}_{0}$ is the initial fraction of the drug in the solution resulting from a burst release, $\boldsymbol{k}_{\mathrm{HB}}$ : Hopfenberg release constant.

Release of pure LCD fit best to first order model where drug release is concentration dependent. In vitro release from chitosan nanoparticles fit best to Korsmeyer-Peppas 
model according to the all criteria. This model indicates diffusion controlled release from a polymeric matrice nano-system developed. ${ }^{9,23}$ ' $n$ ' is the diffusional release exponent that could be used to characterize the different release mechanisms [ $\mathrm{n} \leq 0.45$ (Fickian diffusion), $0.45<n<1$ (anomalous transport) and $n=1$ (case II transports; i.e. zero-order release)]. Korsmeyer-Peppas equation proposed that release of LCD from the polymeric matrice was through Fickian diffusion ( $n=0.290$ and $n=0.420, F-1, F-2$ respectively). This information suggest that the LCD release from the nanoparticles were through diffusion. ${ }^{44}$

\section{CONCLUSION}

In this paper, LCD was used as a model drug to be entrapped into a natural biodegradable material (chitosan) using a spray drying method. Analyses results demonstrated that nanometer sized spherical nanoparticles were achieved with this technique. Also nanoparticles showed narrow size distribution, cationic characteristic and relatively high encapsulation efficiency. Solid state characterization studies such as DSC, FT-IR and ${ }^{1} \mathrm{H}-\mathrm{NMR}$ justified the successful incorporation into the polymeric matrices. It was shown that all nanoparticles displayed a prolonged release pattern without a burst effect in comparison with the pure drug. According to the criteria, formulations were fitted to Korsmeyer-Peppas model demonstrates the diffusion mechanism of polymeric matrices.

In vitro studies showed that cationic chitosan nanoparticles containing LCD are effective carrier candidates for reducing local irritation to GI membranes and other side-effects and optimizing plasma drug concentration that can improve bioavailability and protection the sensitive drug against light, thus also improving the stability. However, in vivo analyses results are required for the final decision to be made.

\section{ACKNOWLEDGEMENT}

The author would like to thank to BIBAM (Anadolu University) management for spray dryer equipments and the author would like to thank to Exp.Serkan Levent (DOPNALAB, Anadolu University) for FTIR and NMR studies.

\section{Conflict of interest}

No conflict of interest was declared by the author. 


\section{REFERENCES}

1. Prabhu P, Malli R, Koland M, Vijaynaryana K, D'Souza U, Harish NM, Shastry CS, Charyulu RN. Formulation and evaluation of fast dissolving films of levocetirizine dihydrochloride. Int J Pharm Investig. 2011;1(2):99-104.

2. Goindi S, Kumar G, Kaur A. Novel flexible vesicles based topical formulation of levocetirizine: in vivo evaluation using oxazolone-induced atopic dermatitis in murine model. J Liposome Res. 2014;24(3):249-257.

3. Takahashi $\mathrm{H}$, Ishida-Yamamato A, lizuka $\mathrm{H}$. Effects of bepotastine, cetirizine, fexofenadine, and olopatadine on histamine-induced wheal-and flare-response, sedation, and psychomotor performance. Clin Exp Dermatol. 2004;29:526-532.

4. El-Say KM, El-Hewl ARM, Ahmed OAA, Hosny KM, Ahmed TA, Kharshoum RM, Fahmy UA, Alsawahli M. Statistical optimization of controlled release microspheres containing cetrizine hydrochloride as a model for water soluble drugs. Pharm Dev Technol 2015;20(6):738-746.

5. Li F, Ji R, Chen X, You B, Pan Y, Su J. Cetrizine dihydrochloride loaded microparticles design using ionotropic cross-linked chitosan nanoparticles by spraydrying method. Arch Pharm Res. 2010;33(12):1967-1973.

6. Vino S, Preethi LR, Gopika M, Ghosh AR. Controlled release formulation of levocetirizine dihydrochloride by casein microparticles. Afr J Pharm Pharmaco. 2013;7(17):1046-1053.

7. Yurtdaş-Kırımlıoğlu G, Yazan Y. Formulation and in vitro characterization of polymeric nanoparticles designed for oral delivery of levofloxacin hemihydrate. Euro Int J Sci Technol 2016;5(4):148-157.

8. Foged C, Brodin B, Frokjaer S, Sundblad, A. Particle size and surface charge affect particle uptake by human dendritic cells in an in vitro model. Int. J. Pharm. (2005);298:315-322.

9. Dash M, Chiellini F, Ottenbrite RM, Chiellini E. Chitosan-A versatile semisynthetic polymer in biomedical applications. Prog Polym Sci. 2011;36:981-1014.

10. Vino S, Paryani P, Sajitha LS, Ghosh AR. Formulation and evaluation of chitosan beads of levocetirizine dihydrochloride. J Appl Pharm Sci. 2012;2(8):221-225. 11. Agnihotri SA, Mallikarjuna NN, Aminabhavi TA. Recent advances on chitosanbased micro- and nanoparticles in drug delivery. J Control Release. 2004;100:5-28. 
12. Başaran E, Yenilmez E, Berkman MS, Büyükköroğlu G, Yazan Y. Chitosan nanoparticles for ocular delivery of cyclosporine A. J Microencapsul. 2014;31(1):4957.

13. Sinha VR, Singla AK, Wadhawan S, Kaushik R, Kumria R, Bansal K, Dhawan S. Chitosan microspheres as a potential carrier for drugs. Int J Pharm. 2004;274:1-33. 14. Re M. Formulating drug delivery systems by spray drying. Dry Technol. 2006;24:433-446.

15. He P, Davis SS, Illum L. Chitosan microspheres prepared by spray drying. Int J Pharm. 1999;187(1):53-65.

16. Corrigan DO, Healy AM, Corrigan OI. Preparation and release of salbutamol from chitosan and chitosan co-spray dried compacts and multiparticulates. Eur $\mathrm{J}$ Pharm Biopharm. 2006;62:295-305.

17. Teeranachaideekul V, Souto EB, Junyaprasert VB, Müller RH. Cetyl palmitatebased NLC for topical delivery of Coenzyme $Q_{10}$ - Development, physicochemical characterization and in vitro release studies. Eur J Pharm Biopharm. 2007;67:141-148. 18. USP (The United States Pharmacopeia), Levocetirizine Dihydrochloride, 2017 http://www.uspnf.com/sites/default/files/USp_pdf/EN/USPNF/iras/levocetirizinedihydrochloride-m3460-ira.pdf.

19. Zhang Y, Huo M, Zhou J, Zou A, Li W, Yao C, Xie S. DDSolver: An add-in program for modelling and comparison of drug dissolution profiles. AAPS Journal. 2010;12(3):263-271 .

20. Sormoli ME, Islam MIU, Langrish TAG. The effect of chitosan hydrogen bonding on lactose crystallinity during spray drying. J Food Eng. 2012;108:541-548.

21. Yenilmez E, Yurtdaş-Kııımlıoğlu G, Şenel B, Başaran E. Preparation, characterization and in vitro evaluation of dirithromycin loaded Eudragit RS 100 nanoparticles for topical application. Lat Am J Pharm. 2017;36(11):2203-2212.

22. Lopedota A, Trapani A, Cutrignelli A, Chiarantini L, Pantucci E, Curci R, Manuali E, Trapani G. The use of Eudragit RS 100/cyclodextrin nanoparticles for the transmucosal administration of glutathione. Eur J Pharm Biopharm. 2009;72:509-520.

23. Öztürk AA, Yenilmez E, Arslan R, Şenel B, Yazan Y. Dexketoprofen Trometamol-Loaded Kollidon ${ }^{\circledR}$ SR and Eudragit ${ }^{\circledR}$ RS 100 Polymeric Nanoparticles: Formulation and In Vitro-In Vivo Evaluation. Lat Am J Pharm. 2017;36(11):2153-2165. 
24. Tan CP, Nakajima M. $\beta$-Carotene nanodispersions: preparation, characterization and stability evaluation. Food Chem. 2005;92:661-667.

25. Honary S, Zahir F. Effect of Zeta Potential on the Properties of Nano-Drug Delivery Systems - A Review (Part 1). Trop J Pharm Res. 2013;12(2):255-264.

26. Radomska-Soukharev A. Stability of lipid excipients in solid lipid nanoparticles. Adv Drug Deliver Rev. 2007;59:411-418.

27. Castelli F, Puglia C, Sarpietro MG, Rizza L, Bonina F. Characterization of indomethacin-loaded lipid nanoparticles by differential scanning calorimetry. Int $J$ Pharm. 2005;304:231-238.

28. Choudhury P, Deb P, Dash S. Formulation and statistical optimization of bilayer sublingual tablets of Levocetirizine hydrochloride and ambroxol hydrochloride. Asian J Pharm Clin Res. 2016;9(5):228-234.

29. Saito Y, Iwata T. Characterisation of hydroxyl groups of highly crystalline-chitin under static tension detected by FT-IR. Carbohydr Polym. 2012;87:2154-2159.

30. Kenawi IM, Barsoum BM, Youssef MA. Drug-drug interaction between diclofenac, cetirizine and ranitidine. J Pharm Biomed Anal. 2005;37:655-661.

31. Sionkowska A, Wisniewski M, Skopinska J, Kennedy CJ, Wess TJ. Molecular interactions in collagen and chitosan blends. Biomaterials. 2004;25:795-801.

32. Ali SM, Upadhyay SK, Maheshwari A. NMR spectroscopic study of inclusion complexes of cetirizine dihydrochloride and $\beta$-cyclodextrin in solution. Spectroscopy. 2007;21:177-182.

33. Shamshad $\mathrm{H}$, Arayne MS, Sultana N. Spectroscopic characterization of in vitro interactions of cetirizine and NSAIDS. J Anal Sci Technol. 2014;5(22):1-8.

34. Yurtdaş-Kırımlıoğlu G, Yazan Y. Development, characterization and in vitro release characteristics of rabeprazole sodium in halloysite nanotubes. Euro Int J Sci Technol. 2016;5(4):99-109.

35. ICH, Q2R1 2005. HarmonisedTripartiteGuideline, Validation of AnalyticalProcedure: Text and methodology, Complementary Guideline on Methodology, in: Proceedings of the International Conference on Harmonization, Canada.

36. Shabir GA. Validation of high-performance liquid chromatography methods for pharmaceutical analysis. Understanding the differences and similarities between 
validation requirements of the US Food and Drug Administration, the US Pharmacopeia and the International Conference on Harmonization. J Chromatogr A. 2003;987:57-66.

37. Yurtdaş-Kırımlıoğlu G, Yazan Y. Determination of gamma-aminobutyric acid by HPLC: Its application to polymeric nanoparticles and stability studies. Int J Develop Res. 2016;6(6):8277-8282.

38. Öztürk AA, Yenilmez E, Yazan Y. Development and validation of high performance liquid chromatography (HPLC) modified method for dexketoprofen trometamol. Euro Int J Sci Technol. 2017;6(4):33-41.

39. Adibkia K, Javadzadeh Y, Dastmalchi S, Mohammadi G, Niri FK, Alaei-Beirami M. Naproxen-Eudragit $\circledast$ RS100 nanoparticles: preparation and physicochemical characterization. Colloids Surf B Biointerfaces. 2011;83:155-159.

40. Thagele R, Mishra A, Pathak AK. Formulation and characterization of clarithromycin based nanoparticulate drug delivery system. Int J Pharm Life Sci. 2011;2:510-515.

41. Zuo J, Gao Y, Bou-Chacra N, Löbenberg R. Evaluation of the DDSolver Software Applications. Biomed Res Int. 2014;ArticleID204925:1-9.

42. Costa P, Sousa Lobo JM. Modeling and comparison of dissolution profiles. Eur J Pharm Sci. 2001;13:123-133.

43. Victor OB, Francis OA. Evaluation of the Kinetics and Mechanism of Piroxicam Release from Lipophilic and Hydrophilic Suppository Bases. Int J ChemTech Res. 2017;10(1):189-198.

44. Sharma UK, Verma A, Prajapati SK, Pandey H, Pandey AC. In vitro, in vivo and pharmacokinetic assessment of amikacin sulphate laden polymeric nanoparticles meant for controlled ocular drug delivery. Appl Nanosci. 2015;5:143-155. 